This item was submitted to Loughborough's Research Repository by the author.

Items in Figshare are protected by copyright, with all rights reserved, unless otherwise indicated.

\title{
An exploration of service design jam and its ability to foster social enterprise
}

\section{PLEASE CITE THE PUBLISHED VERSION}

http://www.drs2016.org/\#drs2016

\section{PUBLISHER}

(c) The Authors. Published by the Design Research Society

\section{VERSION}

AM (Accepted Manuscript)

\section{PUBLISHER STATEMENT}

This work is made available according to the conditions of the Creative Commons Attribution-NonCommercial 4.0 International (CC BY-NC 4.0) licence. Full details of this licence are available at: http://creativecommons.org/licenses/by-nc/4.0/

\section{LICENCE}

CC BY-NC 4.0

\section{REPOSITORY RECORD}

Kuzmina, Ksenija, Chris Parker, Jun Jun, Martin Maguire, Val Mitchell, Maria A. Moreno, and C. Samantha Porter. 2019. "An Exploration of Service Design Jam and Its Ability to Foster Social Enterprise". figshare. https://hdl.handle.net/2134/20772. 


\title{
Future-Focused Thinking
}

\section{An exploration of Service Design Jam and its ability to foster Social Enterprise.}

\author{
Dr Ksenija Kuzmina ${ }^{a^{*}}$, Dr Chris Parker ${ }^{\mathrm{b}}$, Dr Gyuchan Thomas Jun ${ }^{\mathrm{a}}$, Dr Martin Maguire ${ }^{\mathrm{a}}$, Dr Val \\ Mitchella $^{a}$ Dr Mariale Morenoc ${ }^{c}$ Dr Samantha Porter ${ }^{a}$ \\ aLoughborough University, UK \\ ${ }^{\mathrm{b}}$ The University of Manchester, UK \\ ${ }^{\mathrm{c}}$ Cranfield University, UK \\ *Corresponding author e-mail: k.kuzmina@lboro.ac.uk
}

\begin{abstract}
Social enterprises (SE) are valued as innovative solutions to complex problems but require conditions to nurture and support them. Most support systems rely on individuals who already have an SE idea, and there is very little research on understanding what conditions can support to cultivate the willingness and motivation to engage individuals in this activity. An exploratory study was led to understand whether a particular event, Service Design Jam, can provide such conditions. The paper introduces the study of the Lufbra Jam, organised at Loughborough University, from which two social enterprises, Crop Club in 2013, and FrenPals in 2014 emerged. Through literature review desirability and feasibility were extrapolated as key variables to the formation process of social enterprises. A focus group with three Lufbra Jam organisers was led to identify important organisational elements of the Jam that were perceived to have an impact on the formation of the successful SE thus influencing the perception of desirability and feasibility of SE in individuals. The integration of the two created a thematic matrix that was used to analyse findings from the research with the participants of the two successful SE Cases. The research findings suggest that Lufbra Jam enabled individuals to identify socially and environmentally focused issues and formulate service solutions that they deemed to be desirable and feasible. It also provided an insight that winning and an enterprising workshop were important SDJ elements that helped teams to recognise their service ideas not only as feasible solutions but as SE opportunity for the team to take forward.
\end{abstract}

Keywords: service design, social enterprise, social innovation, social value

\section{Introduction}

In the UK, social enterprises (SE) have been recognised as building blocks of the local communities and local economies (Teasdale, 2011; Kennell, 2013). Particularly SE have been actively providing products and services where private and public sectors have failed to provide for the needs of others (Chew and Lyon, 2012). Thus, politically they have been valued as innovative solutions to the increasingly complex social and environmental issues with a focus on the 'local regeneration' (Teasdale, 2011). 
Recently there has been a recognition that these solutions require nurturing and support (Nesta, 2012, Chew and Lyon, 2012). Various means of providing financial support to implement social entrepreneurial ideas or scale up existing ventures have been emerging. For example, consecutive governments have been developing policies and budgets such as Enterprise Investment Scheme (EIS) in 2013 to encourage organisations and individuals to invest into the start-ups and organisations. Oxford Hub and Beyond Business are a few examples that have been arising as support systems to provide funding to individuals with best social entrepreneurial ideas (ibid.).

In most of these cases the support systems rely on individuals who are already willing to engage in an entrepreneurial activity and have solution concepts to the identified problems. However, there is less emphasis on creating conditions that will cultivate the willingness and motivation of an individual to engage in an entrepreneurial activity. NESTA identified the importance of intermediaries to develop 'safe spaces' (NESTA, 2012) where individuals, resources, and ideas can be connected to initiate and grow innovative enterprising solutions. Examples of these are Innovation hubs and research institutes that are usually permanent spaces and require a large amount of resources to be set up and managed.

In this paper the potential of Design Jams that are taking place at the grassroots level to provide such support for individuals in a form of a 'safe event' is evaluated. The literature is reviewed to identify what motivates individuals to pursue setting up a new social enterprise venture and what are the processes and variables that enable it. The process of the three Lufbra Service Design Jams conducted at Loughborough Design School as part of the Global Jam event and entrepreneurial outcomes from these Jams, two 'live' social enterprises; 'the Crop Club' and 'FrenPals' are considered. In the conclusion the processes and variables of the Design Jam that support individuals in engaging with SE activity are identified.

\section{Background Literature}

A common way to define social enterprise is 'a business solution to social [and/or environmental] problem' (Teasdale, 2011: p. 8). It is a unique type of business that is not driven by economic value alone, but has greater moral intentions. Stevenson and Jarillo (1990), suggest that 'moral intention' presupposes an activity that is pursued by an individual. They therefore place the social entrepreneur at the core of social enterprise definition, and redefine it as a process that involves individuals engaging in innovative use of resource combinations leading to solving problems that constrain the creation and sustaining of social/environmental benefits.

Researchers have been focusing on identifying processes and variables that enable this activity. They show that individuals explore desirability and feasibility of the social enterprise idea prior to engaging with it full time (Forster and Grichnik, 2013, Mair and Noboa, 2003). The outcome of this process is based on personal and situational variables (Renko et al., 2012) that act as enablers or barriers to the initial social entrepreneurial activity. 


\subsection{Desirability and feasibility of setting up a social enterprise}

Willingness to take part in social entrepreneurial activities begins by identifying the desirability and feasibility of the new venture (Forster and Grichnik, 2013, Mair and Noboa 2003). Desirability refers to the perceived 'attractiveness' of forming the enterprise, where an individual perceives a problem space and is willing to solve it through an enterprising activity. The problem space or an opportunity that is seen as desirable for an individual relates to their motivation to discover and explore a particular type of opportunity (Mair and Noboa, 2003). Whereas for-profit entrepreneurs are mostly driven by economic goals (Bacq et al, 2014), the motivations of social entrepreneurs are more complex (Boluk and Motiar, 2014; Ross et al, 2012) and may include solving problems that are social, self-developmental and economic (Bacq et al, 2014).

\subsection{Social Entrepreneurial Motivations}

Successfully solving a social or environmental issue is considered to be a primary motivation for social entrepreneurs (ibid.). For some entrepreneurs these issues are derived directly from the needs of others (Ross et al, 2012). In this case, as Mair and Noboa (2003) suggest, empathy, an ability to intellectually recognise and emotionally share another person's emotions and feelings, is triggered to "enable a helping response" (p. 10). Ross et al. (2012) research found, that the problem space can also reflect the needs of the social entrepreneur, for example being unsatisfied with the status quo of a product or a service. However, a social entrepreneur will seek to develop a solution that will bring social or environmental value, rather than value to 'self' only.

Another motivation of social entrepreneurs in starting a new venture is self-development. A study reported by Xavier et al (2012) describes personal growth as one of the factors that individuals pursue in starting a new venture. In line with these findings Ross et al. (2012) identified learning a new skill to be a motivational factor. In addition, they found that social entrepreneurs were motivated by the opportunity to creatively use one's hobby or technical skills to address a new problem space.

Creating enterprise has also been identified as a desirable goal for social entrepreneurs. Ross et al (2012) note that it is not a primary aim of social entrepreneurs, and lack of business skills and managerial knowledge has been a barrier for many to successfully develop SE (Bacq et al, 2014). Yet, motivation for social entrepreneurs is to make their new venture commercially viable, thus sustaining the social/environmental impact (Ross et al, 2012).

\subsection{Social norm}

In addition to individual motivation, perceived social norm is another aspect that leads a social entrepreneur to act (Forster and Grichnik, 2013). In this case an individual perceives social pressure to perform or not to perform a particular behaviour, in this case engaging in enterprising activity. The individual makes the decision to act based on their perception, of whether their activity is viewed as appropriate by the leaders within their community, 
organisation or their close group of family and friends (Krueger and Brazeal, 1994). Thus a 'social norm' within any given group may influence whether entrepreneurial activity is perceived as an opportunity or not.

\subsection{Feasibility, Self-Efficacy}

Feasibility refers to whether one believes that they are capable of putting together the required resources to forming the enterprise (Forster and Grichnik, 2013). Perceived feasibility is grounded in self-efficacy, the conviction of one's capability to successfully perform the task. This perception develops with time through development of knowledge, skills both physical as well as cognitive (Hostager et al, 1998). This evaluation of one's capabilities does not necessarily mean that the task will be performed well. However, the conviction is required for an individual to engage in the activity in the first place.

\subsection{Context of Social Support}

In addition to self-efficacy, social support also relates to the perceived feasibility, as it is recognised that entrepreneurs require external help and cannot operate on their own. Social support is provided through 'collective action' by various stakeholders connected to the entrepreneurs (Corner and Ho, 2010), who are able to provide entrepreneurs with various resources that are needed to facilitate the emergence of the enterprise. Thus social support may range from friends and family, for example small social entrepreneurs usually rely on their friends and family to identify the social and environmental needs of others. Works by Corner and Ho (2010) and Ross et al (2012) points out that identified problems are complex and the solution rarely resides with an individual entrepreneur. These 'wicked problems' (Rittel and Webber, 1973) need a collaborative approach, thus entrepreneurs coalesce with other stakeholders whose knowledge they require to co-create feasible solutions. Finally, entrepreneurs can establish community of users (Ross et al, 2012) who are willing to test out the initial ideas, provide user feedback and increase the perception of feasibility of the initial ideas.

Table 1 Process and variables to support social enterprise activity

\begin{tabular}{|c|c|c|}
\hline Process & & Variables \\
\hline \multicolumn{3}{|l|}{ Category } \\
\hline \multirow[t]{4}{*}{$\begin{array}{l}\text { Enhancing Perception } \\
\text { of Desirability }\end{array}$} & Motivation & $\begin{array}{l}\text { Seeing social/environmental issues as an enterprise } \\
\text { opportunity (Teasdale, 2011) }\end{array}$ \\
\hline & & $\begin{array}{l}\text { Personal dissatisfaction with the 'status' quo (Ross et al. } \\
\text { 2012) / Social Norm (Forster and Grichnik, 2013) }\end{array}$ \\
\hline & & Self-development (Xavier et al., 2012) \\
\hline & & Creating enterprise (Ross et al., 2012) \\
\hline
\end{tabular}




\begin{tabular}{lll}
\hline $\begin{array}{l}\text { Enhancing Perception } \\
\text { of Feasibility }\end{array}$ & Self-efficacy & Physical / Cognitive (Hostager et al, 1998) \\
\cline { 2 - 3 } & Social & Network/resources (Corner and Ho, 2010) support \\
\cline { 2 - 3 } & $\frac{\text { Co-creating solution with others (Rittel and Webber, 1973) }}{\text { Community of users (Rittel and Webber, 1973) }}$ \\
\hline
\end{tabular}

Whilst social support is seen as essential by many, one of the barriers expressed by individuals engaged in entrepreneurial activity has been time and resources to develop such social support and networks). In particular, participating in the wrong networks has been the most frustrating for these individuals (ibid.).

Both the individual and environmental variables, summarised in Table 1, are needed for individuals to engage with social enterprising activity. To cultivate social entrepreneurial activities Forster and Grichnik (2013) suggest that to enhance the perception of feasibility as well as desirability can be achieved by developing a context within which this can happen.

\subsection{What is a Design Jam?}

Design Jams are a recent phenomenon that followed Hackathon events (Vezzani and Tang, 2014) that brought together programmers, graphic, interface designers, and project managers to work intensively on a software project with a digital output (Briscoe and Mulligan, 2014). Design Jams, are conceptually similar, but do not require a digital output, and usually belong to a discipline (ibid.).

\subsection{Emerging area of Service Design}

Service Design is an emerging area of design that seeks to apply design process, methods and principles to the design of service organisations, services, and other social systems, supporting and facilitating their development and improvement (Holmlid, 2007 and Mager, 2004). It is an 'outside in' approach (Holmlid, 2012) where its process may be described as an iterative process of inquiry and action (Steen et.al, 2011). It couples understanding of the past and current situation with exploring and envisioning possible futures (Steen et.al, 2011). Methodologically Service Design engages with theories and methodologies of service management, marketing, human-centred design (HCD), user-experience design, product and interaction design (Polaine, 2012) in order to create new or improve existing services.

\subsection{Service Design and Design Jams}

Recently Service Design community has used Design Jam format to create a Global Service Design Jam (globalservicejam.org, 2015). The Global Jam is a community-supported event and is run on voluntary basis with no staff and no budget. Instead, it relies on a small group of global organisers who provide online central platform, basic rules, and inspiration to the regional Jams that in turn are run by local hosts, volunteers passionate about service design. 
The aim of each regional Design Jam is to bring people with various backgrounds together, on a voluntarily basis, to dedicate 48 hours to co-designing new services that could make the world a better place to live. The focus of the Jam is on the use of human-centred, service design-based approach to problem solving: the problem is introduced to the participants by the global organisers as a 'secret theme' that requires re-interpretation from the jammers. Participants are expected to form teams during the event, and discover, develop and prototype solutions through the event, rather than come with a prepared idea. Throughout the 48 hours, participants are supported by the organisers and mentors, who usually have expertise in innovation, creativity, service design, and project management. The expected outcome of the jam is a physical functioning prototype of a service, ranging from low tech to high tech, and a plan of action that the team can take forward.

\subsection{Literature Conclusion}

To further support emergence of social enterprise a safe environment where individuals can nurture their willingness to engage in social entrepreneurial activity is needed. While the core purpose for the Design Jams is in providing an opportunity to collaborate, share and learn, many aspects of the Jam make it a potential 'safe event' for increasing the desirability and feasibility of the participants to engage in social entrepreneurial activity.

For example, the process of the Jam aims to motivate individuals to be creative in developing solutions that are of value to the world through the human-centred design process. It also encourages them to test the feasibility of their ideas by developing physical prototypes and testing them with their teams. The global dimension of the Jam and an expected outcome of 'a service with a plan of action' makes an idea of the 'service prototype becoming a real SE' a norm within the Jam community. Finally, the community-supported approach to the Jam generates social support that potentially increases self-efficacy and further feasibility of the individuals to pursue SE.

SE knowledge or interest is not a pre-requisite for the Jam and there is no real evidence that the Jam does provide a supporting context for individuals to nurture their willingness to engage in an SE activity. The aim of the study is to reflect on the process of the Lufbra Service Design Jams and the two social enterprises that have been developed as a result, to identify whether a Design Jam, may be defined and designed in the future as a 'safe event' to support SE activity.

\section{Research Methods and Analysis}

As the research objectives of this study were exploratory, seeking to understand how Service Jams may help inspire, foster, and grow social enterprises, an inductive research approach was selected. Importantly, this research was an exploration of people, their thoughts, feelings and reflections, encapsulated within the scope of user research; focusing on the person's subjective perception rather than an objective or definitive expression of predetermined criteria (Rose, 2003). The insights that could help to understand the broad 
range of activities and experiences, from participants' perspective is a unique focus to the SDJ environment that could foster enterprise activities.

As such, it was necessary to understand which organisational elements of the 48 hour event at the Lufbra SDJ influence desirability and feasibility (see Table 1) of the social enterprise process the most. A focus group with Lufbra SDJ organisers was conducted to define these elements and their relationship to the concepts of desirability and feasibility. Then a case study research took place with Jam participants that have been able to set up a social enterprise from the ideas that came out of the event. These were conducted to validate the influence of the organisational elements on the SE process. Due to specific nature of this research project, participants were chosen using a purposive sampling.

To analyse the focus group and case studies, transcripts were produced and analysed following an open coding process with the aid of NVivo (QSR, 2014). A thematic analysis process was followed in which the researchers recognised themes and patterns across the participant experiences and opinions, leading to further sub-themes to be compared and contrasted (Aronson, 1994).

\subsection{Focus Group: SDJ Organisers}

Three members of Loughborough University Design School academic staff who have formed the core of the Lufbra SDJ were selected as participants for this paper's focus group. The focus group lasted 45 minutes, and conducted within the Loughborough University Design School in a semi-public setting by the principal author of this study. In order to address the research aims, the interview questions were generated to identify the core organisational elements before, during and after the Jam.

\subsection{Case Studies: SDJ Participants}

Two enterprises that came out of previous SDJ's were included within the case studies for this paper; The Crop Club and FrenPals. Interviews with the founders of these enterprises were conducted based on the outcomes of the initial focus group, primarily targeting the organisational elements of the Jam with the desirability and feasibility of their new venture as highlighted by Foster and Grichnik (2013); see Table 2. The two social enterprises that were used as case studies are the following:

- The Crop Club led by Dr Rose Deakin (interviewed) grew from the 2013 SDJ at Loughborough University Their focus is on creating a service to connect communities and individuals through sharing of grown produce such as vegetables or orchard/ hedgerow fruit. Over the last two years, The Crop Club has won several awards for enterprise, including Think Big Social Enterprise, Marketest Market Research, and Try It/ Do It from HEFCE and Unltd.

- FrenPals was created by Ibrahim Abdulkarim (interviewed), Siting Yang, and Jaydeep Gandi during the 2014 SDJ at Loughborough University. Their focus is on helping international students settle into university life within a new 
country through connecting with student volunteers (buddies), offering comprehensive support in a variety of contexts.

\subsection{Results}

A summary of the findings within this study is presented within Table 2 below. Table 2 is a matrix integrates the organisation elements from the Jam (across) and the desirability and feasibility variables that are part of the social enterprise process (down). The $X$ 's indicate the answers from the two Case studies where participants felt the Jam's organisational elements support their SE process. Section 4 expands on the thematic analysis of these results. 


\section{Future-Focused Thinking}

Table 2. SE Process and Lufbra Service Design Jam matrix

\begin{tabular}{|c|c|c|c|c|c|c|c|c|c|}
\hline & & & & During Lufbra J & & & & & $\begin{array}{l}\text { fter } \\
\text { am }\end{array}$ \\
\hline PROCESS & 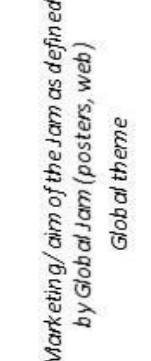 & 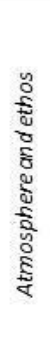 & 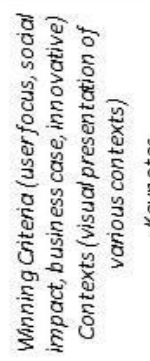 & 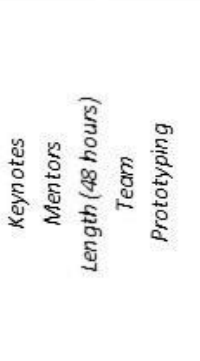 & 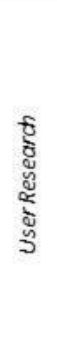 & 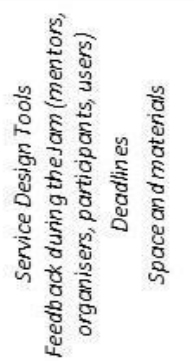 & $\begin{array}{l}\text { षूँ } \\
\text { हี } \\
\text { ठँ } \\
\text { ¿ }\end{array}$ & 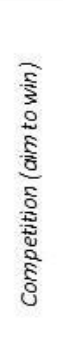 & 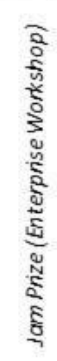 \\
\hline
\end{tabular}

What was your motivation to attend the jam

\begin{tabular}{|c|c|c|c|c|c|c|c|c|}
\hline \multirow{2}{*}{ Enhancing Perception of Desirability } & $\begin{array}{l}\text { What enhanced your perception that } \\
\text { the social problem space exists }\end{array}$ & $x$ & $x$ & $x$ & \multicolumn{2}{|r|}{$x$} & & \\
\hline & $\begin{array}{l}\text { What enhanced your perception that it } \\
\text { is desirable to solve it through social } \\
\text { enterprise activity }\end{array}$ & & $x x$ & $x$ & & & & \\
\hline \multirow{2}{*}{ Enhancing Perception of Feasibility } & $\begin{array}{l}\text { What enhanced your confidence on } \\
\text { feasibility of social enterprise? }\end{array}$ & & & & $x$ & $x$ & $\mathrm{xx}$ & $\mathrm{xx}$ \\
\hline & $\begin{array}{l}\text { When enhanced your confidence on } \\
\text { your team's capability of doing it? }\end{array}$ & & & & $\mathrm{xx}$ & $\mathrm{x}$ & & \\
\hline
\end{tabular}

(C) (5) \$) This work is licensed under a Creative Commons Attribution-NonCommercial 4.0
International License. 


\section{Future-Focused Thinking}

\section{Thematic Analysis}

Thematic analysis introduces the findings from the research. In particular it highlights service design process and service design tools within the Jam event and its relationship with the Social Enterprise process that the participants experienced.

\subsection{Motivation to attend the Jam event}

The main motivations to attend the Jam event by the participants were to do something different, to self-develop and to socialise. The event was marketed as a "48 hour design challenge" and participants, in both cases from art and design, saw this as an opportunity to practice applying their existing skills to the new discipline of design. The Jam positions itself as a 'social collaborative event where participants work in teams', participants were motivated by this opportunity to be in a social environment, collaborate and network whilst solving problems through design, and therefore doing design together. In neither of the cases, was developing an enterprise a motivation to join the Lufbra Jam.

\subsection{General motivation and self-efficacy throughout the Jam}

The original motivations were supported by the organisation of the Jam. The selfdevelopment in both cases was high. The Jam not only allowed for the application of the existing design skills to the problem, but also introduced new design process, methods and tools that participants found valuable. The design process that the participants were presented with and formed the basis of the Jam is known as Double Diamond (Design Council, 2006). It is the process of problem inquiry and solution generation, and within service design is appropriated to the context of services. The tools and methods introduced support this process. For example, the inquiry tools and methods introduced to the participants focused on understanding the use situation as it is experienced by the stakeholders themselves. Participants engaged in research through contextual interviews, capturing and synthesising their understanding in brainstorming sessions, using personas and mind mapping (Figures 1 and 2 ).

This work is licensed under a Creative Commons Attribution-NonCommercial 4.0 International License. 


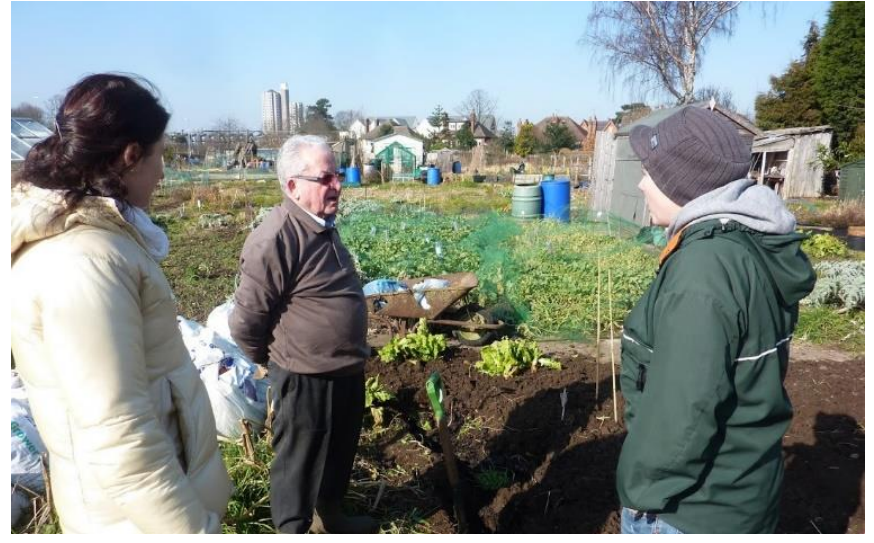

Figure 1 Lufbra Jam participants interviewing allotment owner

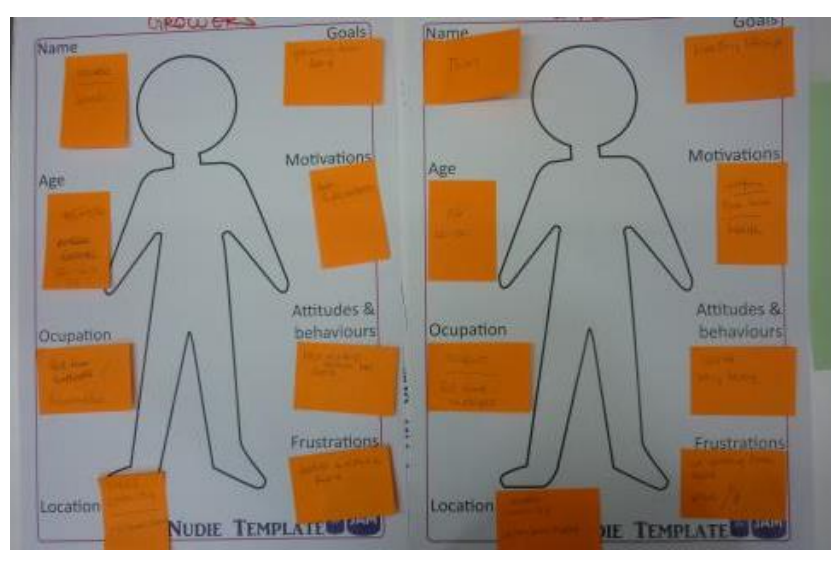

Figure 2 Persona tool used by Case 1 participants

Further generative tools were introduced to the Jammers in order to co-create service visions. Examples of the tools participants engaged with were customer journey maps and storytelling. These tools helped jammers to create consensus on their vision, build visual narratives and communicate their ideas to others (Figures 3 and 4).

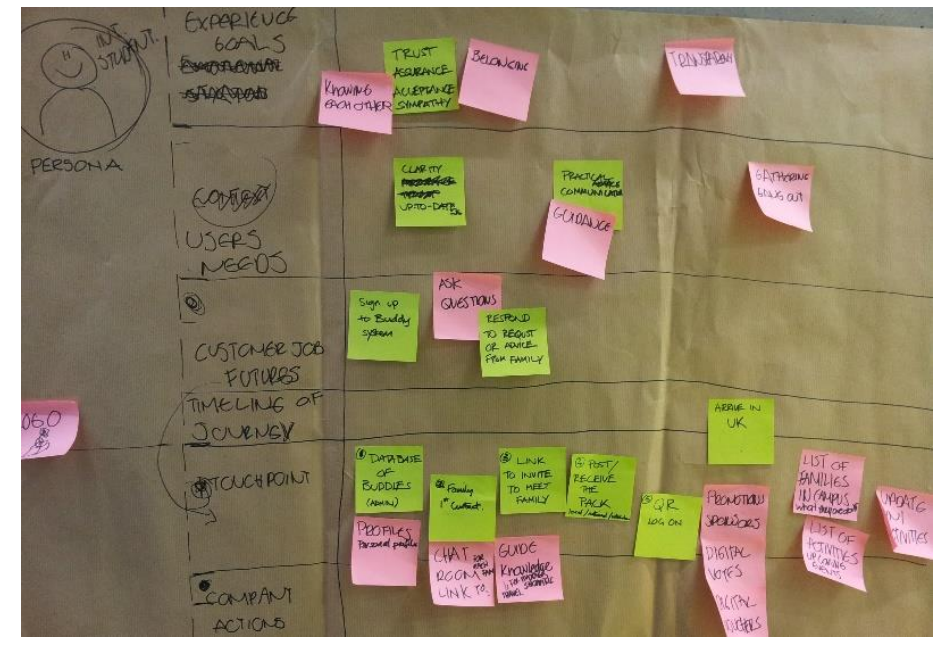

Figure 3 FrenPals initial customer journey

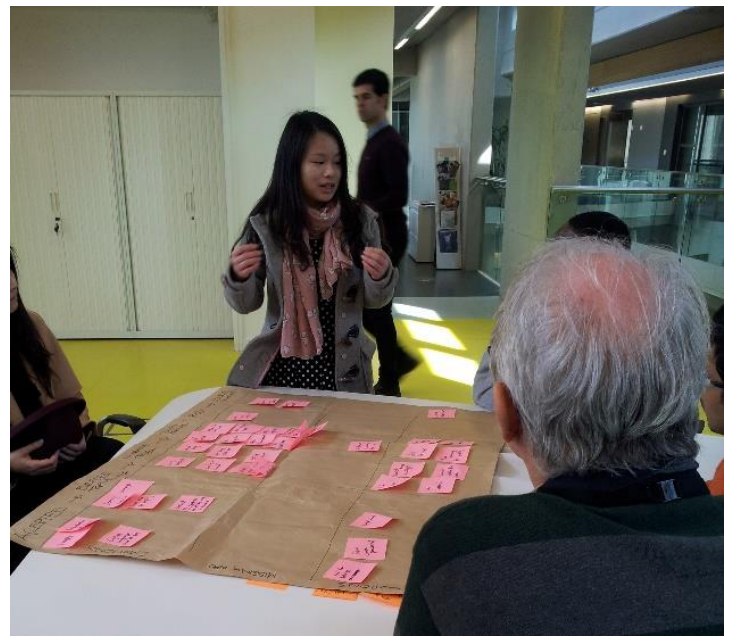

Figure 4 Participant is sharing first service concept with the mentor

Finally, jammers were presented with quick prototyping techniques. These were used by the jammers to collaboratively build their visions, to get as close to the real version of the service as possible, modelling the service and evaluating it. Desktop walkthroughs as well as digital tools such as PopApp were used by the jammers to build their service visions (Figures 5 and 6). This learning opportunity increased self-efficacy of the participants as they developed their solution. 


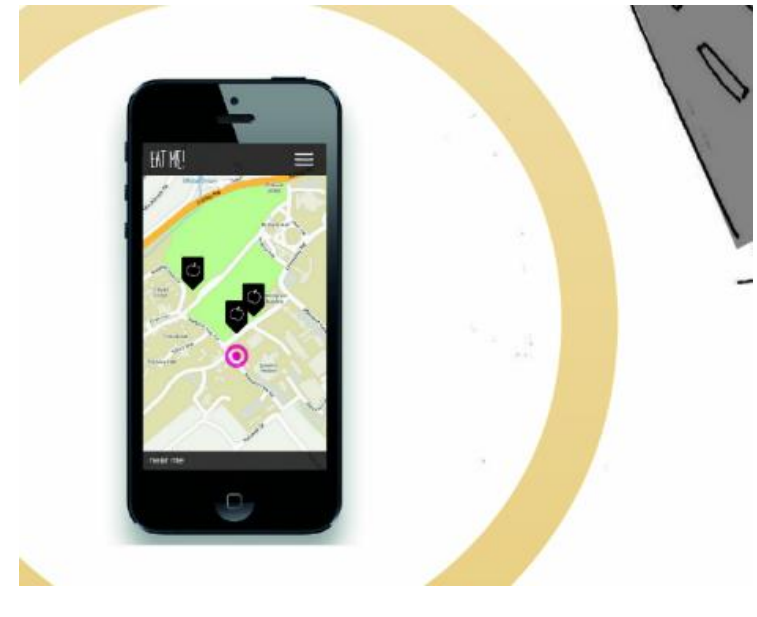

Figure 5 CropClub high fidelity app prototype

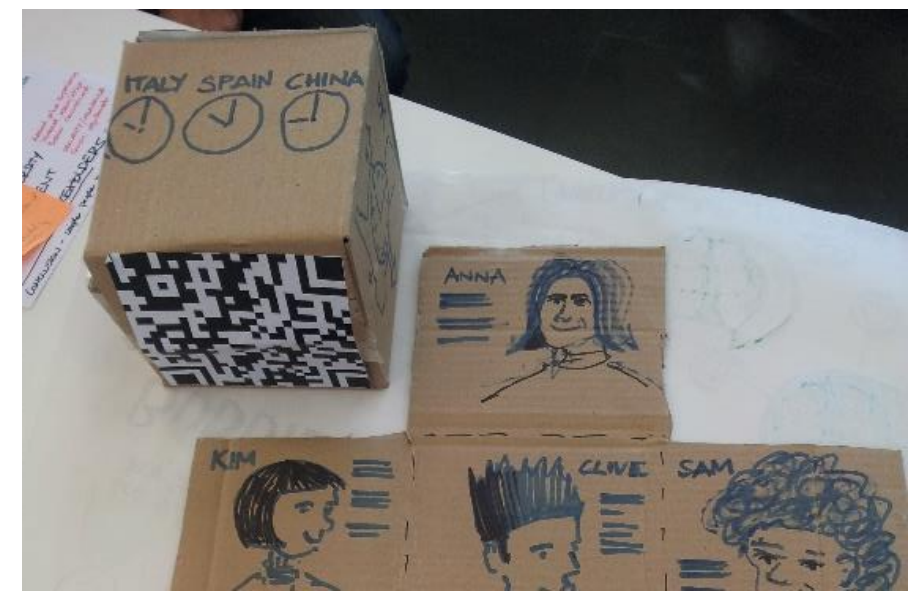

Figure 6 FrenPals low fidelity prototype

Other unexpected opportunities for increased self-efficacy occurred at the Jam. For example, Lufbra Jam invited mentors from the industry who were eager to find new talent. During the Jam one of the participants was invited to a job interview, which increased her self-belief for the duration of the event. The overall social and collaborative environment was created and maintained at the Jam, which helped teams to stay motivated. At the venue the digital screens displayed tweets by the Jammers around the world. This visual representation of the Jam has been noted to give participants a feeling that they are part of a global event, which was motivational in itself. Neither Case 1 nor Case 2 were very much driven by winning the Jam. As the participant in Case 2 says, "the prize was not something so big that it was worth fighting for", instead during the Jam the teams were motivated by the service design process and by the need to develop an innovative solution.

\subsection{Recognition of the social problem space}

The two problem spaces that the participants chose to work on during the Jam were particular issues that they were aware of or experienced themselves prior to the Jam. In the first case a group member observed a pattern within her community that she felt was problematic and felt strongly about. In the second case the problem originated around a personal bad experience. During the Jam these issues were brought to the surface through the global theme and the initial 'speed dating' brainstorm session that Lufbra Jam ran around it. In the first case the theme triggered an idea for a solution to the wider social problem, in the second, it triggered discussions that allowed for the personal issue to be identified. Once groups were formed, these ideas became more permanent. In Case 1 the group members recognised the solution and the wider social issue to be timely and important, with two group members already involved in the activities that were the concern of the identified problem. This prior knowledge of the problem space helped the team to focus on the design of the solution. In Case 2, the group identified the problem space to be important because several group members shared a similar bad personal experience. In the 
next stage of the event, the teams were supported and encouraged to carry out user research, which was in line with the human-centred approach of the service design methodology and the event. For the team 2 this was an important stage as by doing it, they began to validate the problem space as something that was important to others outside the group. It is also at this time that they became motivated by wanting to "help solve that problem for others".

\subsection{Enhancing desirability of social enterprise solution}

The Lufbra Jam criteria set out a vision for the service solutions to be innovative, userfocused, to have a social impact and to be commercially sustainable. Yet, participants in both teams focused on developing the solutions that would cover the first three variables, with less attention to the business case. Both teams felt that although the Lufbra Jam set business case as one of the criteria, the overall atmosphere and the ethos of the Jam was based around generating the value for society and social change. Both teams felt that being run by volunteers and marketed as a creative event, the Jam's organisation was imperative to the outcome being a social enterprise. "If it was set out as a business workshop it would be different" (Case 2).

Throughout the Jam service design tools were introduced to the participants, including personas and customer journey (see section 4.2), with less emphasis on service business tools such as business canvas. These tools are user-centred by their nature, which drove both teams to focus on value their service creates for the user. Case 1 identified business case to be the least of the topics to be covered over 48 hour period by the organisers and mentors.

\subsection{Perceived feasibility of the idea}

Both teams agreed that the 48 hours of the Jam were spent developing their service solution and building confidence in their idea. Participants discussed doing it through having an opportunity to gain greater understanding on the subject of services, for example, Lufbra Jam featured keynote speakers from the design industry, who helped participants to contextualise what service innovation is. In addition participants built knowledge and experience around service design tools and methods. These were introduced by Lufbra Jam organisers (see section 4.2) and applied with the support of Jam mentors to generate service ideas.

At Lufbra Jam each team had a mentor from the design industry. Mentors 'found' their teams organically throughout the first hours of the event, thus finding a relational fit with the rest of the team. In both Cases mentors played a really important role in building the team's confidence in their design capabilities and solution feasibility. Service design is an iterative process, and participants were encouraged to begin with low fidelity prototyping and move on to high fidelity as a result of the several feedback cycles. In both cases this 
allowed mentors to be involved with the teams' service visions, to question them and give feedback whilst allowing the ownership of the ideas to stay with the group.

The collaborative ethos of the Jam also permitted participants to build upon each other's ideas and develop solutions that the whole team believed in. Case 1 participant shared: "The overall vision felt like mine, but how it was developed and delivered wasn't because we did it as a team...even the vision, we discussed and built on it together".

\subsection{Perceived feasibility of the enterprise}

During the 48 hour challenge, both teams noted that they were focused on the idea generation and building capacity in their teams to generate those ideas. At every Lufbra Jam, winners received the prize of an enterprise workshop for one hour with the Glendonbrook Enterprise Office at Loughborough University. The winning of the prize played an important role in providing teams with an additional level of recognition for their ideas. For the team in Case 2, winning was the turning point at which they felt that their idea was feasible enough to be taken forward. For t Case 1, winning was not enough. It was at the workshop, when they received the positive feedback on their idea from the enterprise experts and were introduced to some strategies on developing an enterprise that they began to believe their work could be turned into a real life project. In both cases the winning prize of the Lufbra Jam, not only gave a brief introduction to the business elements of the social enterprise, but motivated the teams to take their work further. Both teams sought and received external funding, and are currently hosted by The Studio, a professional space at Loughborough University that not only provides access to physical facilities but also business support and guidance.

\section{Discussion}

This paper highlighted that Lufbra Jam is an event that can support several elements of the successful social entrepreneurial development. It provides an insight into how in a very short period of time individuals can be supported to generate and develop ideas for the services that are socially focused and recognised as desirable and feasible. It also provides an insight into the need for the structured support of taking a developed design solution and increasing its feasibility as a social enterprise, which Lufbra Jam does not achieve.

The findings show that participants had personal motivation to join the event, mainly to selfdevelop. This expectation was met by the Jam, which provided space to learn, do practical design, and network. However, the motivation to develop services that were socially and environmentally focused was partially directed by the ethos of the Jam. This ethos or 'social norm' (Forster and Grichnik, 2013) of the Jam was focused on the creation of the social value and emerged through such elements as the criteria, user research and organisational set up. 
During the event the teams worked on formulating their problem-solution spaces and confirming their desirability on the wider scale. The findings suggest that the problems and solutions that teams worked with already pre-existed within some individuals. The Jam was able to 'tease them out' (Corner and Ho, 2010) through such activities as provision of the Global theme and brainstorming. In addition to teasing out these ideas from the individuals the Jam, encouraged collaborative teamwork, as well as user research, which helped teams to identify the problem-solution spaces with the wider needs of the society.

Further into the 48 hours, participants developed some self-efficacy in working within their team on a design project and in their own capability as designers. The feasibility of their solution ideas was also tested through the social support that included mentors, users, other participants and judges.

However this was not enough to convince the teams that these solutions are desirable and feasible as social enterprise. It is the winning of the Jam in combination with the enterprise workshop that helped the teams to recognise their solution as an entrepreneurial opportunity. An hour entrepreneurial workshop, an opportunity exclusively developed for the winning teams, introduced teams to the basics of an enterprising activity. The workshop was led by the individuals who were passionate about turning ideas into enterprise opportunities, motivating the teams. Thus the winning of the Lufbra Jam based on its winning criteria and the subsequent enterprise workshop supported the team's perceptions of their solutions to be desirable as an enterprise solutions.

However, what the Lufbra Jam did not facilitate was the team's service ideas to develop into feasible social enterprises. However, at that stage the team dynamics changed with some team members leaving and the more prominent members arising. The self-efficacy of some of the teams was strong enough to take the ownership of their solutions and seek further support including external funding or a membership in an enterprise hub, such as the Studio at Loughborough University

\section{Conclusion}

This paper explores Service Design Jam, as a support system to facilitate development of the social enterprises. It looks at Lufbra Service Design Jam, organised by Loughborough University for three consecutive years, from which two social enterprises emerged. Findings from the research suggest that various Lufbra Jam elements were able to support individuals in developing desirable and feasible socially and environmentally solution. The winning and the prize contributed to individuals' increased self-efficacy and recognition of their solution to be further developed as SE. However, participants relied on external support systems to increase the feasibility of their solutions to become SEs 
There is little research on how SE opportunities develop and this paper contributes to this discussion. However, this study is limited by the purposive sampling but is indicatory of the wider phenomenon, further research on other Jams and Hackathons is needed.

Acknowledgements: The authors would like to thank the participants from the Crop Club and FrenPals social enterprises for their contribution to this research. They would also like to thank Loughborough University for their ongoing support of the annual Lufbra Service Design Jam event.

\section{References}

Aronson, J. (1994), "A pragmatic view of thematic analysis", The Qualitative Report, Vol. 2 No. 1, pp. 1-3.

Bacq, S., Hartog, C., \& Hoogendoorn, B. (2014). Beyond the Moral Portrayal of Social Entrepreneurs: An Empirical Approach to Who They Are and What Drives Them. Journal of Business Ethics, 1-16.

Briscoe, G., \& Mulligan, C. (2014). Digital Innovation: The Hackathon Phenomenon (No. 6). CreativeWorks London Working Paper.

Chew, C., \& Lyon, F. (2012). Innovation and social enterprise activity in third sector organisations. Third Sector Research Centre Working Paper Series, 83.

Corner, P.D. and Ho, M. (2010), "How Opportunities Develop in Social Entrepreneurship", Entrepreneurship Theory and Practice, Vol. 34 No. 4, pp. 635-659.

Fallon, G. and Brown, R.B. (2002), "Focusing on focus groups: lessons from a research project involving a Bangladeshi community", Qualitative Research, Vol. 2 No. 2, pp. 195208.

Forster, F. and Grichnik, D. (2013), "Social Entrepreneurial Intention Formation of Corporate Volunteers", Journal of Social Entrepreneurship, Taylor \& Francis Group, Vol. 4 No. 2, pp. $153-181$.

Groenewald, T. (2004), "A phenomenological research design illustrated", International Journal of Qualitative Methods, International Journal of Qualitative Methods, Vol. 4 No. 1, pp. $1-25$.

Haefliger, S., Jäger, P., \& Von Krogh, G. (2010). Under the radar: Industry entry by user entrepreneurs.Research policy, 39(9), 1198-1213.

Hostager, T. J., Neil, T. C., Decker, R. L., \& Lorentz, R. D. (1998). Seeing environmental opportunities: effects of intrapreneurial ability, efficacy, motivation and desirability. Journal of Organizational Change Management,11(1), 11-25.

Kennell, J. (2013) 'Social Enterprise and Employment in the United Kingdom' in Perspectives on Work, Vol.16 (1-2), pp.21-23.

Krueger, N. and Brazeal, D. (1994) "Entrepreneurial potential and potential entrepreneurs",Entrepreneurship Theory \& Practice, Vol. 18 No. 3, pp. 91-104.

Lendel, V. and Varmus, M. (2011), "Creation And Implementation Of The Innovation Strategy In The Enterprise", Economics \& Management, Vol. 16 No. 1, pp. 819-825.

Mair, J., \& Noboa, E. (2006). Social entrepreneurship: How intentions to create a social venture are formed. In Social entrepreneurship (pp. 121-135). Palgrave Macmillan UK.

Murray, R., Caulier-Grice, J., Mulgan, G.(2010) The Open Book of Social Innovation. London: The Young Foundation. 
Orhan, M. and Scott, D. (2001), "Why women enter into entrepreneurship: an explanatory model", Women in Management Review, MCB UP Ltd, Vol. 16 No. 5, pp. 232-247.

Parker, C.J., May, A.J. and Mitchell, V. (2012), "Understanding Design with VGI using an Information Relevance Framework", Transactions in GIS: GISRUK Special Issue, Vol. 16 No. 4, pp. 545-560.

QSR. (2014), NVivo 10, QSR International, Melbourne, Australia.

Renko, M., Shrader, R. C., \& Simon, M. (2012). Perception of entrepreneurial opportunity: a general framework. Management Decision, 50(7), 1233-1251.

Rittel, H. W., \& Webber, M. M. (1973). Dilemmas in a general theory of planning. Policy sciences, 4(2), 155-169.

Rose, D. (2003). Collaborative research between users and professionals: peaks and pitfalls. The Psychiatrist, 27(11), 404-406.

Ross, T., Mitchell, V. A., \& May, A. J. (2012). Bottom-up grassroots innovation in transport: motivations, barriers and enablers. Transportation Planning and Technology, 35(4), 469-489.

Stevenson, H. H., \& Jarillo, J. C. (1990). A paradigm of entrepreneurship: Entrepreneurial management. Strategic management journal, 11(5), 17-27.

Teasdale, S. (2011). What's in a name? Making sense of social enterprise discourses. Public policy and administration, 0952076711401466.

Todd J. Hostager, Thomas C. Neil, Ronald L. Decker, Richard D. Lorentz, (1998) "Seeing environmental opportunities: effects of intrapreneurial ability, efficacy, motivation and desirability", Journal of Organizational Change Management, Vol. 11 Iss: 1, pp.11- 25

Vezzani, V., \& Tang, T. (2014). Investigating the Potential of Design Jams to Enhance Sustainable Design Education. DS 81: Proceedings of NordDesign 2014, Espoo, Finland 2729th August 2014.

Xavier, S.R., Ahmad, S.Z., Nor, L.M. and Yusof, M. (2012), "Women Entrepreneurs: Making A Change from Employment to Small and Medium Business Ownership", Procedia Economics and Finance, Vol. 4, pp. 321-334.

About the Authors:

Dr Ksenija Kuzmina is a lecturer in Design Innovation and Management at the Institute for Design Innovation at Loughborough University, London. Her research investigates issues around service design methodology, social innovation, systems thinking, sustainable design and organisational change.

Dr Christopher Parker is a Lecturer in CAD at The University of Manchester. His research interests are consumer behaviour, service design, anthropometrics and ergonomics.

Dr Gyuchan Thomas Jun is a Lecturer in Human Factors and Complex Systems at Loughborough Design School. His research interests include participatory design, systems thinking and healthcare service design.

Dr Martin Maguire is a lecturer and a research fellow at Loughborough Design School. His main research interests include the design and usability of interactive systems including the needs of inexperienced users, older people and people with disabilities. 
Dr Val Mitchell is a senior lecturer at Loughborough Design School specialising in the development of methods and tools for User Centred Design (UCD). Her research encompasses service design, co design and the use of creative methods to study the home.

Dr Mariale Moreno is a research fellow at the RECODE Network at Cranfield University. Her work focuses on user-centred design, consumer behaviour, sustainable production and consumption, and business opportunities towards achieving a Circular Economy.

Dr Samantha Porter is a Senior Lecturer in Design Ergonomics at Loughborough Design School. Her research interests include. Product pleasure, tools and methods for designing for emotion, the design of the person/product interface of medical related products, personalisation and product attachment leading to sustainability and the design of bereavement services. 
